\title{
STUDY OF CLINICAL PROFILE OF DIABETES MELLITUS IN HOSPITALIZED PATIENTS IN A RURAL TEACHING INSTITUTE IN SUB HIMALAYAN POPULATION: A PROSPECTIVE ANALYSIS
}

\begin{tabular}{ll} 
Dr Guriqbal Singh & Md Medicine \\
\hline $\begin{array}{l}\text { Dr Äbhimanyu } \\
\text { Patial }{ }^{*}\end{array}$ & $\begin{array}{l}\text { Md Medicine, Medical Officer Che Dheera, Distt Kangra. }{ }^{*} \text { Corresponding } \\
\text { Author }\end{array}$ \\
\hline Dr Priya Dhora & Jr Pathology, Dr Rpgmc Tanda,kangra \\
\hline \hline
\end{tabular}

ABSTRACT Introduction: Diabetes mellitus is a major public health problem worldwide. Its prevalence is On rise in many part of developing world and india is no exception. Individual with diabetes mellitus are considered as high priority as they are potential candidates for rapid evaluation to prevent and halt the progression of the complications. Aim : To evaluate clinical profile of Diabetes mellitus in hospitalised patients inDr.R.P.G.M.C Tanda at Kangra.Results : Study include 200 patients, out of which 103 was male and 97 were female. 95(47.5\%) patients had HbAlc level between 6.5-7.5\%, followed by 69(34.5\%) patients in 7.6-8.5\%. Most common cause for hospital admissonin diabetics was infections, $80(40.0 \%)$, followed by Acute coronary syndrome $66(33 \%)$ patients, followed by stroke(14\%) and hypergylcemic emergency(13.5\%). Urinary tract infection was most common infection encountered in our study(31\%), followed by pneumonia (25\%), followed by pulmonary tuberculosis (19\%). STEMI was more common than NSTEMI in our study. ECHO finding suggest $41.48 \%$ had features of left ventriculat systolic dysfunction, $34.04 \%$ patients had features of left ventriculat diastolic dysfunction, and $24.46 \%$ patients had left ventricular hypertrophy. $14 \%$ of patients presented with neurologigal deficit, later diagnosed to had stroke, most commonly it was ischemic stroke, in 18 patients and haemorrhgic stroke in 10 patients. 20(10\%) patients presented with uncontrolled hyperglycemia, out of which 13 patients diagnosed as HHS and \&7 with diabetic ketoacidosis . $60(30 \%)$ patients had feature of diabetic retinopathy.34 had mild NPDR, 23 patients had moderate NPDR and 3 had sever NPDR. Neuropathy was seen in $24 \%(48)$ patients. Dyslipidemia was more commnly seen in our study, more than $95 \%$ patients had LDL level above optimal range, $62 \%$ had TG above optimal range, and $78 \%$ had hypercholesteronem. Conclusion :In our study patients with diabetes mellitus, most of the patients presented with features of infection followed by acute coronary syndrome followed by stroke and hyperglycemic emergencies. UTI was the most common infection encountered followed by pneumonia and pulmonary tuberculosis.Among patients with ACS, STEMI was more common in diabetics as compared to NSTEMI, but female patients presented with NSTEMI. Ischemic stroke was more common in the study we conducted.Microvascular complication of diabetes mellitus were also very common in our study.Majority of the patients who were hospitalised had uncontrolled diabetes and had longer duration of diabetes.

KEYWORDS :

\section{INTRODUCTION}

Diabetes Mellitus (DM) is a metabolic disorder of multiple etiology characterized by chronic hyperglycemia with disturbances of carbohydrate, fat and protein metabolism resulting from defects in insulin secretion, insulin action, or both. The prevalence of DM is increasing worldwide with estimated projection of approximately 300 million patients worldwide by year 2025. India has been recognised as the diabetes capital of the world by the international diabetes federation with approximately around 40.9 million people affected by diabetes as of 2006 . This number is projected to rise to 69.9 million by 2025 . In the Indian diabetes population, the prevalence of macrovascular complications such as coronary artery disease and peripheral vascular disease has been reported as 21.4 and $6.3 \%$ respectively. In the same population, the prevalence of microvascular complications such as microalbuminuria and diabetic nephropathy was reported as 26.9 and $2.2 \%$ respectively. ${ }^{1.4}$ Population growth, aging, urbanization and increasing prevalence of obesity are some of the root causes of increase in diabetes burden in the world. As WHO rightly predicts that developing countries bear the brunt of this epidemic in the 21 st century, we see more than $70 \%$ of people with diabetes live in low and middle income countries. India has an estimated 50.8 million people living with diabetes. The largest age group is currently $40-59$ years and this is expected to move to $60-79$ years age group by the year 2030 with some 196 million cases (World Health Organization). Most of the available literature on diabetes is from studies based on urban population and studies in developed countries. Moreover, the inference from studies on western population or urban population may not be uniformly applicable to the rural setup. Hence, the present study was aimed to study clinical profile of diabetes in hospitalized patients.

\section{SUBJECTS AND METHODS}

A total of 200 diebetic patients aged $>18$ years were included in this study over a period of one year at Department of Medicine, Dr RPGMC Kangra at Tanda. The patients aged $<18$ years, unable to provide consent, and lost to follow-up were excluded from the study.

A complete medical history was obtained with special emphasis on diabetes relevant aspect such as weight loss, family history of diabetes and its complications, risk factors for cardiovascular disease, prior medical condition, exercise, smoking and ethanol use. Routine investigations like RBS, FBS, completehemogram, renal function test, liver function test, urine routine microscopy, lipid profile and $\mathrm{HbAlc}, \mathrm{ABG}$, serum bicarbonate levels, urinary and plasma ketone and troponin I in selected patients according to clinical condition.

Glycated HbAlc reflects average glycemic control over a period of 2-3 months. HbAlc assay by High Performance Liquid Chromatography (HPLC) method is standard reference method. Hemoglobinopathies, haemolytic anemias and uremia may interfere with $\mathrm{HbAl} \mathrm{c}$ result.

\section{STATISTICAL ANALYSIS}

Data were presented as frequency, percentages.

\section{RESULTS}

General characteristics

Table 1 shows general characteristics of the study population. 
$63 \%$ of the patients aged more than 60 years. $51.5 \%$ of these patients were males. Only $7.5 \%$ had duration of diabetes less than 5 years. $70 \%$ of these patients also had hypertension. Only $10 \%$ patients had family history of diabetes.

$\mathrm{HbAlc}$

Majority of patients 95(47.5\%) had HbAlc level between 6.5$7.5 \%$, followed by $69(34.5 \%$ ) in $7.6-8.5 \%$, followed by $14(7 \%)$ in 8.6-9.5\% HbAlc level (Figure 1).

\section{Reason for admission to the hospital}

The patients admitted in medicine ward during study are presented with multiple complaints at same time for eg. Patients presented with classical symptom also have feature of infective etiology and DKA or HHS. Similarly patients with myocardial infarction also had history of infection prior to and during admission. Majority of patients $71.5 \%$ had feature of polyuria, polydypsia (Table 2).

\section{Infection}

80 patients had symptom of infection at time of admission. Out of 80 patients $25(31 \%)$ patients had symptom of urinary tract infection , 20(25\%) patients had pneumonia, 15(19\%) patients later diagnose to have tuberculosis, $10(12 \%)$ patents present with diabetic foot infection and $10(12 \%)$ had symptom of upper respiratory tract infection (Figure 2).

\section{Stroke}

Out of total patients, 28 patients presented with feature of neurological deficit due to stroke, and out of 28 patients 18 had ischemic stroke and 10 had hemorrhagic stroke (Figure 3).

\section{Myocardial infarction}

Total of 66 patients presented with ACS, out which 37patients had STEMI, and 29 patients had NSTEMI (Figure 4).

\section{DISCUSSION}

In our study, the subjects were included from medicine wards. The study included 200 patients detected within one year of the 200 patients studied 103 were males and 97 were female, maximum number of patients were in 60-70 age group Followed by $50-60$ year. In our study maximum number of participants had history of diabetes between 10-15 year followed by 6-10 year. If we consider the clinical presentation at the time of admission to hospital, most of the patients had multiple problems at time of admission, Most of the patient presented with feature of classical symptom( Polydypsia, Polyphagia, Polyuria) also had features of infection, most commonly urinary tract infection, similarly many patients with recent history of infection present with acute coronary syndrome or hyperglycaemic emergencies eg. DKA and HHS. In our study nearly $71.5 \%$ had classical symptom like polyuria, polydypsia and weight loss. This compared with UKPDS were nearly 60-65\% patients were with classical symptoms. About 80 ( $40 \%$ ) patient had symptom of infection. Out of 80 patients, 25 (28\%) had urinary tract infection, 20 (25\%) patients had pneumonia, Most of the time diagnosis of pneumonia was made on radiological and sputum examination, $15(18.5 \%)$ patients had pulmonary tuberculosis, $10(12 \%)$ patients had diabetic foot infection, and $10(12 \%)$ had feature of URTI at time of admission. Urinarytract was the most common site of infection in diabetics. Although most urinary tract infections in diabetics were asymptomatic, but the presence of diabetes predisposed to more severe infection. Tuberculosis was once a common in diabetics patients. In 1930 tuberculosis was 3- 16 times frequent indiabetics. Currently, tuberculosis is less of problem in diabetics patients,Howeverdiabetes may still predispose to reactivation of tuberculosis. Foot infections are common and serious problems in diabetics patients. Infection may develop in the toe nail bed, beneath planter calluses or in ischaemic or neuropathic ulcer. Once established these infections may extend to involve deeper soft tissue, joints or bones. The result of our study was comparable tostudy conducted by Abdul et al. ${ }^{5}$ In our study 28 patients were present with stroke. Out of 28 patients 18 suffered from ischemic stroke and 10 suffered from haemorrhagic stroke. Finding of our study were consistent with many other studies which suggest that diabetics are more prone to ischemic stroke, A study conducted by Sarkar et $\mathrm{al}^{6}$, and study by Ali et al. ${ }^{7}$ On pattern ofstroke in diabetics and non-diabetics, showed diabetics were more likely to have ischemic stroke.

In our study population only 66 (33\%) showed acute myocardial infarction. Out of which $37(56.06 \%)$ patients showed STEMI, 29(43.93) showed NSTEMI. In our study STEMI in male was $59.45 \%$ and NSTEMI was $44.82 \%$, and in female STEMI was $40.54 \%$ and NSTEMI was $55.17 \%$. Result of our study was consistent with the study done by Misiriya et $a l^{8}$. However, In CREATE stud they found that most $(60.6 \%)$ presented with STEMI and only $39.4 \%$ patients presented with NSTEMI. Among males STEMI was more common than female, NSTEMI/UA were also more common in males than females. ${ }^{9}$

\section{CONCLUSION :}

In our study patients with diabetes mellitus, most of the patients presented with features of infection followed by acute coronary syndrome followed by stroke and hyperglycemic emergencies. UTI was the most common infection encountered followed by pneumonia and pulmonary tuberculosis.Among patients with ACS, STEMI was more common in diabetics as compared to NSTEMI, but female patients presented with NSTEMI. Ischemic stroke was more common in the study we conducted.Microvascular complication of diabetes mellitus were also very common in our study.Majority of the patients who were hospitalised had uncontrolled diabetes and had longer duration of diabetes. This again further emphasis the importance of glycaemic control in patients of diabetes.

\section{Table 1. General characteristics}

\begin{tabular}{|c|c|c|c|}
\hline $\begin{array}{c}\text { Age-group } \\
\text { (Year) }\end{array}$ & $<30$ & 4 & 2.0 \\
\cline { 2 - 4 } & $31-40$ & 2 & 1.0 \\
\cline { 2 - 4 } & $41-50$ & 28 & 14.0 \\
\cline { 2 - 4 } & $51-60$ & 42 & 21.0 \\
\cline { 2 - 4 } & $61-70$ & 86 & 43.0 \\
\cline { 2 - 4 } & $71-80$ & 30 & 15.0 \\
\cline { 2 - 4 } & $>81$ & 8 & 4.0 \\
\hline \multirow{4}{*}{ Sex } & Male & 103 & 51.5 \\
\cline { 2 - 4 } & Female & 97 & 48.5 \\
\cline { 2 - 4 } & $<5$ & 15 & 7.5 \\
\cline { 2 - 4 } & $6-10$ & 55 & 27.5 \\
\cline { 2 - 4 } & $11-15$ & 65 & 32.5 \\
\cline { 2 - 4 } & $16-20$ & 51 & 25.5 \\
\cline { 2 - 4 } & $21-25$ & 12 & 6.0 \\
\cline { 2 - 4 } & $>25$ & 2 & 1.0 \\
\hline Hypertension & Normal & 60 & 30 \\
\cline { 2 - 4 } & Hypertension & 140 & 70 \\
\hline Family history & Present & 21 & 10.5 \\
\cline { 2 - 4 } of diabetes & Absent & 179 & 89.5 \\
\hline
\end{tabular}

Table 2: Reason for admission to hospital

\begin{tabular}{|l|l|l|}
\hline Presentation & No. of Patients & Percentage \\
\hline $\begin{array}{l}\text { Classical (Polydypsia, } \\
\text { Polyuria, Polyphgia) }\end{array}$ & 143 & 71.5 \\
\hline Infections & 80 & 40.0 \\
\hline Myocardial infarction & 66 & 33 \\
\hline Stroke & 28 & 14 \\
\hline DKA & 7 & 3.5 \\
\hline HHS & 13 & 6.5 \\
\hline
\end{tabular}




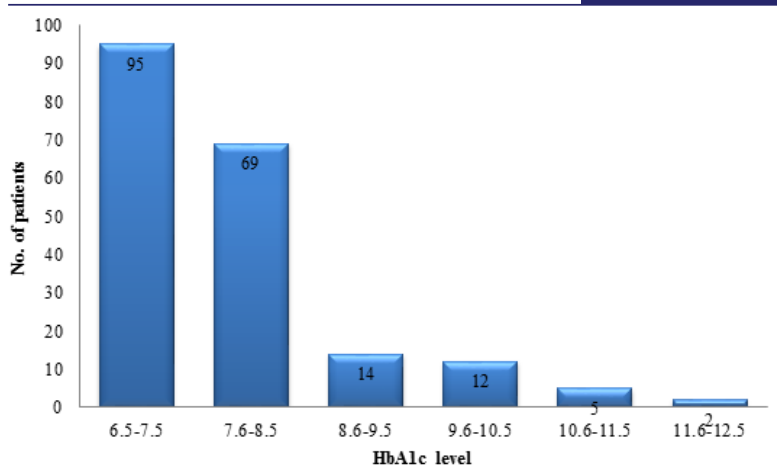

Figure 1. Distribution of $\mathrm{HbAlc}$ levels among diabetic patients

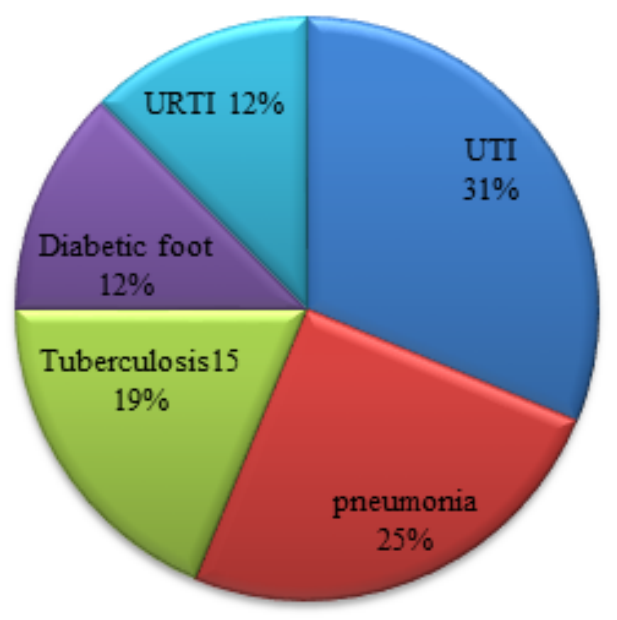

Figure 2. Distribution of infection among diabetic patients

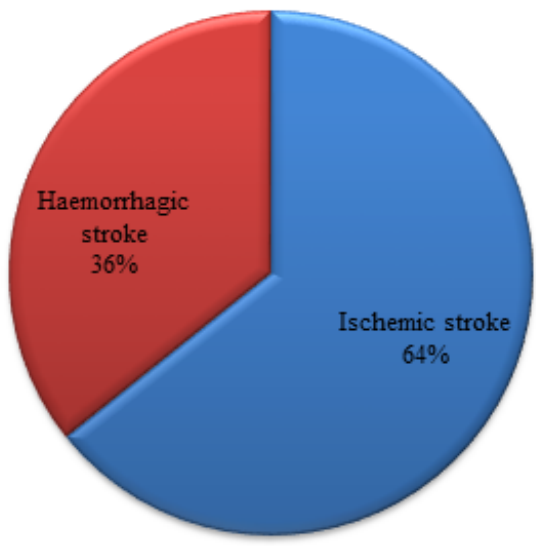

Figure 3. Distribution of stroke among diabetic patients

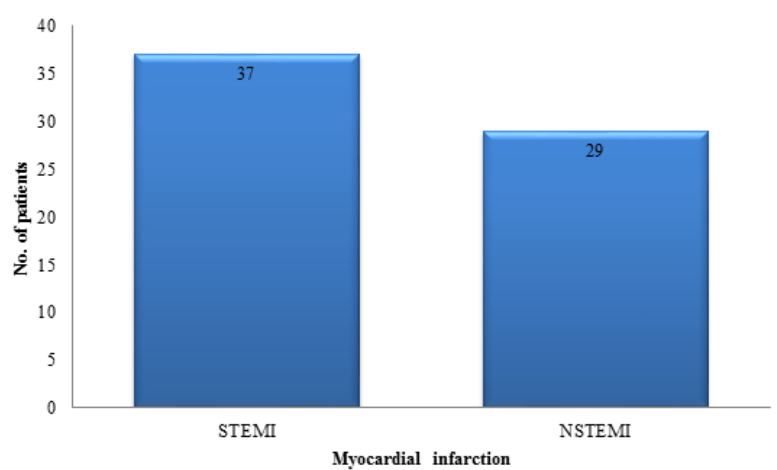

Figure 4. Distribution of myocardial infarction among diabetic patients

\section{REFERENCES}

1. King H, Aubert RE, Herman WH. Global burden of diabetes, 1995-2025: prevalence, numerical estimates, and projections. Diabetes Care.1998 September 1; 21(9): 1414-1431.

2. Sicree R SJZP. Diabetes and impaired glucose tolerance.: Diabetes Atlas, International Diabetes Federation. 2006: 15-103.

3. Mohan V, Sandeep S, Deepa R, Shah B, Varghese C. Epidemiology of type 2 diabetes: Indian scenario. Indian J Med Res. 2007 March; 125(3): 217-230.

4. Unnikrishnan R, Rema M, Pradeepa R, Deepa M, Shanthirani CS, Deepa R, et al. Prevalence and Risk Factors of Diabetic Nephropathy in an Urban South Indian Population. Diabetes Care.2007 August; 30(8): 2019- 2024.

5. Abdul HZ, Shariq RM, Bashir AL, et al. Incidence and pattern of infectionin Diabetes Mellitus A Retrospective Study. Int JDiabDev Countries 1994;14:82-4.

6. Sarkar RN, Banerjee S, Basu. A Comparative evaluation of diabetic and nondiabetic stroke-effect of glycemia on outcome. J Indian Med Assoc 2004;102:551-3

7. Ali R, Kazmi S, Iqbal MZ. Pattern of stroke in diabetics and nondiabetics.Journal of Ayub Medical College Abbottabad. 2013 Jun 1;25(1-2):89-92

8. Misiriya KJ, Sudhayakumar N, Khadar SA, George R, Jayaparkasht V.LPappachanJM.The clinical spectrum of acute coronary syndrome: experience from major centre in Kerala.JAssoc Physicians India. 2009 May; $57: 377-83$.

9. Selim S, Rahman R, Yasmin R, Karim N, Chowdhury SH, Lona H, et al. Risk factor of acute coronary syndrome among Bangladeshi people.Mymensingh Med J.2013 Jul;22(3):513-21. 